

\section{ÍNDICE}

Introducción.

AnTón Alvar

\section{Historiografía de la ESClaVitud y PENSAMiento POLÍtico}

1. Objets, matérialités et organicités de la condition servile: la conscience esclavagiste dans le discours historiographique. 21 Anastasia D. Serghidou

2. La antigüedad esclavista: ideología y política en la construcción de un discurso histórico (ss. XVIII-XIX).

Bernat Montoya

3. La esclavitud en los Estados Unidos

y el activismo de la memoria. .75

Montserrat Huguet

4. Jefferson y la esclavitud en el Mundo Clásico. Clelia Martínez 
5. La historiografía de la dependencia antigua en el ambiente de la explotación contemporánea

Domingo Plácido

6. Esclavage(s) et comparaison(s).

Remarques historiographiques..

JaCQues ANNEQuin

7. Historia de las clases trabajadoras:

El Esclavo (Fernando Garrido) 161

Alberto Prieto

8. La esclavitud como tema: de la pintura a la historiografía y la cultura política a fines del siglo XIX en España. 175 Antonio DUplá

\section{Historiografía DE LA ESCLAVITUd EN ORIENTE Y GRECIA}

9. La esclavitud en la Antigua Mesopotamia según la Asiriología soviética. La propuesta de Vasili V. Struve. 195 JORDI VIDAL

10. Los persas como esclavos en la historiografía...... .207 Borja Antela - Clàudia ZaragozÀ

11. George Grote y los hilotas. .221

CÉSAR FORNIS 
12. Historiografía de los thetes.

Miriam VALDÉs

13. El retorno de la diosa Penia. La historiografía

sobre la pobreza en la antigua Grecia.

Aida Fernández

\section{Historiografía de LA ESClAVITUd \\ en la Península Ibérica y Roma}

14. Storiografia greca e latina sulle guerre

servili della tarda repubblica.

.291

Paolo Desideri

15. Pline le Jeune sociologue des pratiques

esclavagistes de son temps?

.301

Antonio Gonzales

16. El enemigo «atípico» en las fuentes literarias

antiguas relativas a los conflictos de finales de la

República romana. Itálicos, esclavos y «fuera de la ley»

.325

Isaías Arrayás - Carlos Heredia

17. Ciccotti e il problema della schiavitù

Elena Caliri

18. Notas sobre la cuestión de la esclavitud

en la obra de Gaetano de Sanctis. .363

Jordi Cortadella - César Sierra 
19. Las revueltas serviles como modelo democrático:

la Weltanschauung de Masaoki Doi en Japón

durante la Guerra Fría

Antón Alvar

20. Esclavitud y dependencia en la historiografía

española sobre la Península Ibérica: aproximación

a una controversia continua.

María J. Hidalgo

21. Historiografía de la esclavitud en el ámbito ibérico.

Teodoro Crespo - Jaime Alvar

22. El mundo rural en el sistema provincial romano:

una reflexión historiográfica para el Noroeste hispano

Inés SAstre - Antonio Rodríguez - Brais X. Currás

23. El trabajo en las minas antiguas. Visiones historiográficas

Elena Zubiaurre - Alejandro Beltrán 


\title{
GEORGE GROTE Y LOS HILOTAS ${ }^{1}$
}

\author{
César Fornis \\ Universidad de Sevilla
}

EN EL PRIMERO DE LOS ARTÍ́culos DE LA SERIE Les assassins de la mémoire, concebida para denunciar el silencio y el negacionismo del genocidio judío por los nazis, Pierre Vidal-Naquet recordaba a tal propósito el pasaje de Tucídides (4.80.2-4) en el que relata cómo, en el momento más delicado para Esparta de la guerra del Peloponeso, los espartiatas seleccionaron a dos mil hilotas con el pretexto de su liberación, les coronaron y les hicieron recorrer los santuarios, para poco después hacerles desaparecer sin que se supiera de qué manera, en la creencia de que los más audaces y fuertes serían también los más dispuestos a rebelarse. El estudioso francés subrayaba que las palabras «muerte», «eliminación» $\mathrm{o}$ «destrucción» no son pronunciadas, aunque

1. Este artículo se inscribe en el marco del proyecto de investigación HAR2015-63549-P. 
obviamente están implicadas: los hilotas simplemente desaparecen sin dejar rastro y solo un tenue hilo de memoria llegó hasta Tucídides².

La supresión del recuerdo de la masacre de los hilotas ha acompañado en este caso a la masacre en sí, pero otro tanto podría decirse de la existencia misma del hilotismo, conspicuamente ausente de la historiografía moderna -y en general del pensamiento y la cultura occidentales- hasta fechas relativamente recientes. Ello no solo se justifica por el secreto que envolvía todo lo concerniente al Estado lacedemonio (como se queja el hijo de Oloro en 5.68.2), sino también porque, al ser los hómoioi o ciudadanos espartanos de pleno derecho un modelo de virtudes, de libertad y de patriotismo para esa tradición occidental -lo que se conoce como mirage espartiate desde la feliz acuñación de François Ollier ${ }^{3}-$, los hilotas eran invisibles, pese a que era su trabajo forzado el que liberaba a sus dueños de las labores manuales para entregarse por entero a la comunidad política. Cuando desde la primera mitad del siglo XIX el paradigma espartano comience a dar síntomas de agotamiento y se vaya abriendo paso el ateniense, siendo determinante en el proceso la obra de George Grote, la situación no experimentará apenas variaciones dada la indiferencia de la corriente historiográfica positivista hacia las clases dependientes.

George Grote es sin lugar a dudas el exponente más visible, el escaparate podríamos decir, de la «revolución» en la historiografía británica e incluso europea sobre la antigua Grecia ${ }^{4}$. Su influencia ha sido tan vasta y profunda que Paul Cartledge bromea con que habría que sustituir el tradicional B.C. (before Christ) por B.G. (before Grote)

2. P. Vidal-Naquet, "La destrucción de los ilotas de Esparta", en Id., Los asesinos de la memoria, México, 1994 (1987), 136-139.

3. F. Ollier, Le mirage spartiate. Étude sur l' idéalisation de Sparta dans l'antiquité grecque, I-II, París, 1933-43.

4. En general sobre Grote: A. Momigliano, "Georges Grote and the Study of Greek History”, en Id., Contributo alla storia degli studi classici, Roma, 1955, 213-231; E.F. Dow, "George Grote, Historian of Greece", Classical Journal, 51, 1956, 211-219; F.M. Turner, The Greek Heritage in Victorian Britain, Londres-New Haven, 1981, passim; D. Plácido, "Nacionalismo, imperialismo y democracia: la Historia de Grecia de George Grote", Revista de Occidente, 152, 1994, 25-36; J.T. Roberts, Athens on Trial. The Antidemocratic Tradition in Western Thought, Princeton, 1994, 238-252; W.M. Calder III y S. Trzaskoma (Eds.), George Grote Reconsidered. A 200th Birthday Celebration with a First Edition of his Essay "Of the Athenian Government", Hildesheim, 1996; D. Demetriou, George Grote on Plato and Athenian Democracy: A Study in Classical Reception, Frankfurt, 1999; Id. (Ed.), Brill's Companion to George Grote and the Classical Tradition, Brill's Companions to Classical Reception 1, Leiden, 2014.

5. En la introducción (p. xi) a la edición «condensada» de la History of Greece en la editorial Routledge (2001). 
Es también en buena medida el responsable del criticismo hacia Esparta que imperó en el resto del siglo XIX ${ }^{6}$. En efecto, la monumental $A$ history of Greece, from the earliest period to the close of the generation contemporary with Alexander the Great, en doce volúmenes (London, 1846-1856, con traducciones al alemán, francés e italiano) ${ }^{7}$, del banquero, parlamentario liberal y radical filosófico, sublimó el régimen democrático ateniense, incluso el más demótico o «demagógico», el encarnado por Pericles y Cleón -lejos de la «moderación» soloniana-, al tiempo que ensombrecía los logros de los lacedemonios y criticaba la legislación y el deshumanizado sistema educacional impuesto por Licurgo. Como escribió el autor de una reseña, «no se puede amar al mismo tiempo a Atenas y a Esparta», así que Grote hubo de cercenar la muy longeva y arraigada idealización de Esparta en el pensamiento occidental (o por lo menos abrir un largo paréntesis, pues resurgirá con renovado brío durante el nacionalsocialismo ${ }^{8}$. Largamente difundido, además de bendecido por un crítico de la estatura intelectual de John Stuart Mill, el trabajo de Grote, a quien se conocería en adelante como «el historiador de Grecia», fijó el canon en la historiografía de la Antigüedad griega de la Inglaterra victoriana, por más que el cuadro de la Atenas democrática e imperial del siglo V a.C. que pintaba recordara en gran medida al parlamentario y naval imperio británico del XIX.

Ahora bien, ni en el concepto ni en el método historiográfico de Grote tienen relevancia los hilotas, salvo en contados acontecimientos como el mencionado, que golpeó la sensibilidad del historiador victoriano por el ejercicio de fría y calculada crueldad de los espartiatas, pero también porque demostraba en Esparta «la ausencia no solo de debate público, sino de curiosidad pública»'; de no ser por la autoridad de Tucídides como fuente, Grote hubiera vacilado en creerlo: For this dark and blood deed Thucydides is our witness, and Thucydides describing a contemporary matter into which he had inquired ${ }^{10}$. Pero no solo lo cree, sino que lo juzga y lo eleva, como Vidal-Naquet, a la categoría de

6. P. Cartledge, “Grote's Sparta / Sparta's Grote”, en Demetriou, Brill's Companion... op. cit., 255272 selecciona y comenta tres temas/pasajes como ejemplos de la representación «salvajemente negativa en su mayor parte» que de las instituciones y acciones espartanas hizo Grote en su obra.

7. Cito según la nueva edición de 1869-70, también en 12 vols. (Londres, Murray).

8. Demetriou, George Grote... op. cit., 119.

9. Vol. II, 376-377.

10. Vol. II, 377. En realidad, Tucídides no es la única fuente: Diod. Sic. 12.67.4, basado en Éforo, cuenta lo mismo, con la diferencia de que en su relato los hilotas son asesinados en sus casas. La mayoría de historiadores modernos, como Grote, tiende a aceptar la veracidad del episodio, aunque algunos lo han puesto en duda (R.J.A. Talbert, "The Role of the Helots in the Class Struggle at Sparta”, Historia, 38, 1989, 222-240; M. Whitby, “Two Shadows: Images of Spartans and Helots”, en A. Powell y S. Hodkinson (Eds.), The Shadow of Sparta, Londres, 1994, 87-126) y según otros habría sido amplificado (A. 
genocidio: «Tal estratagema, tan pérfida en la planificación, tan asesina en el propósito y tan completa en la ejecución, permanece sin paralelo en la historia griega -podemos casi decir, sin paralelo en cualquier historia $»^{11}$. Muy significativamente una reciente historia mundial del genocidio y del exterminio publicada por la Universidad de Yale arranca precisamente de Esparta, presente ya desde el subtítulo: from Sparta to Darfur $^{12}$. Este episodio por sí mismo, sin ninguna otra evidencia dice Grote, expresa «cuán poco los hábitos de una asamblea pública se hubieran adaptado al temperamento o al funcionamiento de gobierno de los espartanos» ${ }^{13}$. De esta forma, sin necesidad de hacer un estudio socioeconómico del hilotismo -hubiera sido insólito para su época-, Grote afronta el tema desde un punto de vista exclusivamente político, para arrojar sombras sobre el «carácter inhumano del gobierno lacedemonio», tan alejado de la democracia ateniense que él admiraba ${ }^{14}$.

Por lo general las alusiones a los hilotas que salpican la Historia de Grote son parcas, se limitan meramente a consignar su participación -en ocasiones antes o después de ser liberados (brasideos y neodamodes)- en las campañas del imperio lacedemonio de finales del siglo $\mathrm{V}$ y principios del $\mathrm{IV}^{15}$, su mención preventiva en la tregua que precedió a la paz de Nicias ${ }^{16}$, o bien los daños, fundamentalmente militares, que causaban su establecimiento en Naupacto y Pilos/Corifasio por los atenienses ${ }^{17} \mathrm{o}$ sus revueltas contra la clase dirigente espartiata, como la masiva que siguió al gran seísmo del año 464, de la que ignora la amenaza que supuso para la supervivencia del orden establecido ${ }^{18}$. También pasa de puntillas, aceptando sin tapujos una vez más el testimonio de Tucídi-

Paradiso, "The Logic of Terror: Thucydides, Spartan Duplicity and an Improbable Massacre", en T.J. Figueira (Ed.), Spartan Society, Swansea, 2004, 179-198).

11. Vol. VI, 146-147.

12. B. Kiernan, Blood and Soil. A World History of Genocide and Extermination from Sparta to Darfur, New Haven-Londres, 2007. En cinco páginas (45-49), Esparta es caracterizada como una precursora del genocidio y como «un estado secretista, militarista y expansionista que practicó frecuentes expulsiones de extranjeros y que demostró capacidad para el asesinato en masa» (p. 45).

13. Vol. II, 377.

14. En unas notas escritas en su juventud, deudoras del concepto de «simpatía» de Adam Smith, Grote deja ya claro que para él el grado de civilización alcanzado es directamente proporcional a la administración de sufrimiento sobre otros seres humanos y, en este sentido, él entiende que la vida política democrática en Atenas estaba libre de esa violencia; cf. Demetriou, George Grote... op. cit., 1819 con n. 56.

15. Fundamentalmente a lo largo de los vols. VI, VII y IX.

16. Vol. VI, 212, 277.

17. Vol. V, 189, 444 (Naupacto); VI, 92-98, 131, 145-146 (Pilos/Corifasio).

18. Vol. V, 171-172, 189. 
des (1.132.4-5), sobre las controvertidas pruebas de que Pausanias el Regente fomentó la revuelta de los hilotas - a quienes habría prometido no solo la libertad, sino también la ciudadanía- como parte de sus planes para derrocar a los éforos y convertirse en tirano $^{19}$. Sospecha asimismo que las potenciales revueltas que los éforos temían que organizaran los espartiatas capturados en Esfacteria a su regreso a Esparta tras la paz de Nicias, algunos de los cuales eran hombres que destacaban por riqueza y nacimiento, serían de hilotas, concebidas como vía instrumental para recuperar el poder y los privilegios perdidos con su rendición ${ }^{20}$; Tucídides (5.34.2) no dice esto y del pasaje se desprende más bien que los éforos privaron temporalmente a estos hómoioi de la plena ciudadanía para eludir una stásis interna dentro de la clase dominante (como la que presumiblemente se desató con la conducta y las maniobras políticas del vencedor de Platea). Más analítico se muestra con el prâgma de Cinadón, apreciando que la narrativa de Jenofonte «nos permite un vistazo, aunque tristemente transitorio e imperfecto, a los peligros internos del gobierno espartano», si bien yerra en involucrar a hilotas y periecos en una conjura que implicó exclusivamente a «inferiores» (hypomeíones), esto es, ciudadanos que habían perdido su estatuto y sus privilegios, y puede que -y aquí Grote sí es probablemente correcto- a hilotas liberados y pseudointegrados en el dâmos (neodamódeis) ${ }^{21}$. En los acontecimientos que siguen al desastre espartano en Leuctra, Grote describe con detalle las operaciones militares de this distinguished man que era Epaminondas durante la invasión de Laconia y la liberación de Mesenia, «entregada a periecos e hilotas, convertidos ahora en libertos», así como la fundación de Mesene y Megalópolis, cuyas fronteras serían vigiladas por esos «libertos» junto a los mesenios

19. Vol. V, 125-126. Sobre los problemas que presenta el excurso tucidídeo sobre Pausanias, véase ahora C. Fornis, "Pausanias el Regente y la stásis en la clase dirigente espartiata tras las guerras médicas", Polis, 27, 2015, 27-38, donde se concluye que la stásis instalada en la clase dirigente espartiata como consecuencia del «uso» que había de darse a la victoria en las guerras médicas se resolvió con el triunfo de las fuerzas centrípetas sobre las centrífugas, de la colectividad sobre el individualismo y de la autoridad oligárquica, encarnada por éforos y gérontes, sobre la real, todo lo cual contrasta con el período inmediatamente anterior, dominado por la fuerte personalidad y el imperialismo descarnado del rey Cleómenes I.

20. Vol. VI, 293.

21. Vol. IX, 70-77 (la cita en 76-77). La conspiración de Cinadón es fruto de la coyuntura histórica que vive Esparta con el cambio de siglo, cuando los problemas para la clase dominante espartiata no vienen de la clase hilota, sino del propio cuerpo cívico y de su «aledaños» (cf. C. Fornis, "La conspiración de Cinadón: ¿paradigma de resistencia de los dependientes lacedemonios?”, Studia Historica. Historia Antigua, 25, 2007, 103-115). 
regresados de la diáspora ${ }^{22}$; se subraya la escisión territorial, pero se echa en falta como mínimo alguna referencia a cómo la privación de la tierra y de los hilotas que la habitaban y cultivaban para los hómoioi significó un golpe mortal al sistema de explotación económica de naturaleza esclavista por el cual el hilotismo garantizaba el sostenimiento de la elite sociopolítica del Estado lacedemonio.

Es en el capítulo VI de la segunda parte del volumen II donde Grote lleva a cabo una aproximación a la institución del hilotismo, en el contexto de la obra de Licurgo, a quien por cierto exonera de haberla fundado ${ }^{23}$. Para él la situación de los hilotas apenas difiere en la práctica de la de los periecos: «la distinción entre la población de una ciudad y de una aldea parece ser la principal base para el diferente trato que se da a periecos e hilotas» ${ }^{24}$. Es sintomático que en numerosas ocasiones los hilotas comparezcan junto a los periecos, como si se equipararan los estatutos de ambos, según hemos visto más arriba en la actuación de Epaminondas o, por ejemplo, a la hora de afirmar -probablemente influido por el testimonio erróneo de Isócrates (12.181)- que unos y otros podían ser ejecutados sin juicio previo, a diferencia de los ciudadanos ${ }^{25}$. En otras palabras, los hilotas no serían esclavos. Los define como adscripti glebae, es decir, «colonos o siervos ligados a la tierra que era propiedad de espartanos, y probablemente de periecos propietarios también, a los que pagarían su renta $»^{26}$. Admite por tanto el sistema de la apophorá tal y como es descrito por Plutarco (Mor. 239D-E) o Pausanias (4.14.4), es decir, como una relación contractual, lo cual parece incompatible con el estatuto servil inherente al hilotismo y a la esclavitud misma; no es lo habitual en un historiador que tiende a mostrar un cierto y sano escepticismo hacia la información de este tipo de fuentes tardías que no se vea corroborada por fuentes «fiables» como Heródoto, Tucídides, Jenofonte, Platón o Aristóteles, según hace con el testimonio plutarqueo acerca de la distribución igualitaria de la propiedad por parte de Licurgo, que con buen criterio rechaza como ficticia, forjada a mediados del siglo III y proyectada al pasado más arcano para legitimar las reformas de los reyes Agis IV y Cleómenes III ${ }^{27}$. La armonía constitucional, que habría aportado la proverbial estabilidad sociopolítica y evitado la

22. Vol. IX, 432-451.

23. Vol. II, 379. Pese a reconocer el importante elemento legendario en la tradición que hace de Licurgo el demiurgo creador del kósmos lacedemonio, Grote no duda de su historicidad y le data a finales del siglo IX, cronología en la que sigue a Tucídides una vez más (cf. vol. II, 340).

24. Vol. II, 374.

25. Vol. IX, 439-440.

26. Vol. II, 373.

27. Vol. II, 380-408. Sobre este último tema, véase C. Fornis, "Bajo el signo de Licurgo: el reformismo atávico de Agis IV y Cleómenes III”, Espacio, Tiempo y Forma (Historia Antigua), 28, 2015, 19-37. 
temida stásis, es también desechada como mera falacia ${ }^{28}$. Y sin embargo, su espíritu crítico no se muestra tan exigente con las fuentes tardías sobre los hilotas mesenios, condicionadas por un proceso de reinvención de la historia mesenia iniciado tras la «refundación» de Mesene por Epaminondas en 369 y destinado a limpiar el estigma de casi tres siglos de esclavitud que pesaba sobre este pueblo ${ }^{29}$, ya que de otra forma no se explica la aseveración de que «las distintas anécdotas sobre el trato a los hilotas traducen menos crueldad que ostentoso desprecio ${ }^{30}$. Piensa por ejemplo que es una exageración el testimonio de Mirón de Priene en cuanto a que los hilotas eran azotados anualmente pese a no haber cometido ninguna falta y que se mataba a los que destacaban por su belleza o estatura ${ }^{31}$. Su conclusión, similar a la de Thirlwall (vid. infra), es que no eran inferiores a cualquier población campesina de Grecia ${ }^{32}$. Casi dos siglos después de la obra de ambos autores, sigue sin haber consenso entre la comunidad científica y no son pocos los historiadores que aún ven en los hilotas «campesinos dependientes rurales» ${ }^{33}$, habiendo incluso quien habla de ¡una casta inferior! ${ }^{34}$.

En lo relativo al régimen de propiedad no es menor la controversia. Grote pensaba, igual que a lo largo de toda la tradición occidental, que los hilotas pertenecían al Estado y ello, según él, les posibilitaba «desarrollar simpatías domésticas y sociales», lo que unido a «un cierto poder de adquirir propiedades y la conciencia de su linaje y dialecto griego» les otorgaba «una superioridad sobre los extranjeros que formaban la poblaciones esclavas de Atenas y Quíos» ${ }^{35}$. Aunque cada uno con sus matices, muchos estudiosos se mantienen hoy fieles a la idea de que los hilotas eran esclavos comunitarios, propiedad de la comunidad política lacedemonia, y los hómoioi tan solo los usu-

28. Vol. II, 359-360.

29. Acerca de la construcción y evolución de la identidad mesenia puede verse: L. Pearson, "The Pseudo-History of Messenia and its Authors", Historia, 11, 1962, 397-426; S.E. Alcock, "The PseudoHistory of Messenia Unplagged”, Transactions of the American Philological Society, 129, 1999, 133 141; Th.J. Figueira, «The Evolution of Messenian Identity», en S. Hodkinson y A. Powell (Eds.), Sparta. New Perspectives, London, 1999, 211-244; y, en especial, N. Luraghi, The Ancient Messenians. Constructions of Ethnicity and Memory, Cambridge, 2008.

30. Vol. II, 375.

31. Vol. II, 379.

32. Vol. II, 375.

33. En los últimos años, véase v.gr. E. Lévy, Sparte. Histoire politique et sociale jusqu'à la conquête romaine, París, 2003, 120-121.

34. J. Christien, «Évolution / révolution. Sparte de 260 à 188 av. J.-C.», en M. Debidour (Ed.), Économies et sociétés dans la Grèce égéenne, Nantes, 2007, 239-286.

35. Vol. II, 375. 
fructuarios $^{36}$. Fue a finales del siglo pasado cuando se empezó a cuestionar tal axioma para postular que el hilotismo no deja de enmarcarse en un sistema de propiedad privada, por más que éste se viera arropado por una noción de colectivismo que habría sido considerablemente alentada por los reyes reformadores del siglo III a.C., Agis IV y Cleómenes III, y que habría calado hondo en fuentes posteriores a dicho período como Estrabón o Pausanias, las que más explícitamente hablan de una propiedad comunitaria $^{37}$. Grote, por tanto, sigue aquí también plenamente vigente.

Tampoco se han producido cambios significativos en lo que se refiere a la génesis del hilotismo. Grote reconocía que la pregunta de si, antes de la conquista doria, los hilotas habían sido dependientes de los aqueos o bien independientes, debía quedar sin respuesta $^{38}$. Y hoy seguimos inmersos casi en la misma oscuridad. Hay que recordar que las fuentes situaban los comienzos del hilotismo en la conquista lacedemonia de Helos, cuyos infortunados habitantes habrían dado origen al nombre de hilotas (Helá-

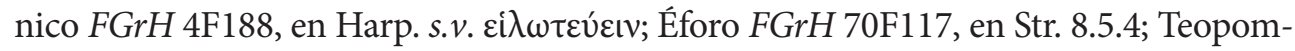
po $F G r H$ 115F13, en Ath. 272A; Paus. 3.20.6), salvo un Antíoco de Siracusa ( $F G r H$ $555 \mathrm{~F} 13$, en Str. 6.3.2) para quien los primeros hilotas fueron los lacedemonios, quizá periecos, que rehusaron ir a la primera guerra mesenia. La asociación entre Helos e hilota/hilotismo es etimológicamente imposible ${ }^{39}$-más plausible es la interpretación acogida por el Etymologicum Magnum de que el término es un aoristo del verbo ع́ı $\lambda \omega$, que significa «capturar», "hacer prisionero» ${ }^{40}$ - y carece por lo demás de lógica que el

36. Sirvan de ejemplos: H. Singor, "Spartan Land Lots and Helot Rents", en H. Sancisi-Weerdenburg et al. (Eds.), De agricultura: In memoriam Pieter Willem de Neeve, Amsterdam, 1993, 31-60; P. Cartledge, "Raising Hell? The Helot Mirage: A Personal Re-View”, en N. Luraghi y S.E. Alcock (Eds.), Helots and their Masters in Laconia and Messenia, Cambridge, 2003, 17-20; Lévy, Sparte... op. cit., 122-124 habla de una propiedad compartida, ni totalmente privada, ni totalmente colectiva.

37. J. Ducat, Les Hilotes, Bulletin de Correspondance Hellénique, Suppl. XX, París, 1990, 19-29 fue el iniciador. Además: S. Hodkinson, Property and Wealth in Classical Sparta, Londres, 2000, 113-149; Luraghi, The Ancient... op. cit.; Id., "Helotic Slavery Reconsidered", en A. Powell y S. Hodkinson (Eds.), Sparta: Beyond the Mirage, Swansea, 2002, 227-248; Id., "The Imaginary Conquest of the Helots", en Luraghi y Alcock, Helots... op. cit., 109-141; M. Lupi, "Le origini di Sparta e il Peloponneso arcaico", en M. Giuangiulio (Ed.), Storia d'Europa e del Mediterraneo. Il mondo antico, II.3: Grecia e Mediterraneo dall' VIII secolo a.C. all'età delle guerre persiane, Roma, 2007, 381-382.

38. Vol. II, 374.

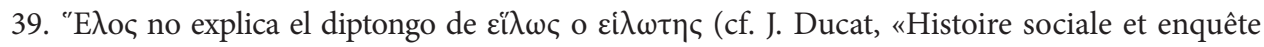
linguistique: le mot 'hilote' et sa famille», en Nomina rerum. Hommage à Jacqueline ManessyGuitton, Niza, 1994, 178-179).

40. Otros verbos de la misma familia significan «oprimir», "presionar». Sobre las diferentes flexiones, la etimología y la familia de la palabra «hilota», consúltese con beneficio Ducat, "Histoi- 
hilotismo hubiera comenzado en Helos y no con la invasión heraclida del Peloponeso, como cabría esperar en una conquista cimentada en la etnicidad ${ }^{41}$. Las tradiciones acogidas por Antíoco y Éforo sugieren que la situación no debió de ser diferente de la que se produce en otros estados griegos, con una evolución interna de la sociedad que conduce al campesinado dependiente y más empobrecido a la esclavitud, como en Atenas, donde quizá la obra de Solón impidió que los hectémoros corrieran la misma suerte que los campesinos laconios hilotizados, dorios o no $^{42}$.

Precisamente a propósito de la cuestión étnica, Grote considera que la mayoría de los hilotas, tanto laconios como mesenios, son dorios $^{43}$. Como ha enfatizado Domingo Plácido, es reseñable que Grote supiera sortear los criterios raciales imperantes en su época, sistematizados por Karl Otfried Müller en el caso del dorismo (en Die Dorier, de 1824), para defender ya entonces que los hilotas, lo mismo que los periecos, no eran menos dorios que los espartiatas, desarmando de esta forma el argumentario germánico que servía para explicar los conflictos internos en el mundo griego antiguo ${ }^{44}$. En el marco de una concepción en la que la estirpe prevalece en las bases formativas, estructurales y definitorias de cualquier comunidad, Müller describía a los dorios como el Stamm griego más genuino y a Esparta como el ejemplo par excellence de dorismo, un Estado modélico por sus instituciones y costumbres, en suma, el arquetipo de $\mathrm{He}$ rrenvolk; claro que por Esparta Müller entendía exclusivamente a los espartiatas, dado que en su construcción racial periecos e hilotas no participaban de ese dorismo, algo que obviamente es erróneo. Frente a una Atenas abierta y «liberal», Esparta encarna bien el estado robusto, hermético y de sólida unidad nacional que prefigura un estado alemán jerarquizado y militarizado, aunque en estos años se trate aún de Prusia (de hecho Müller llama a los espartiatas, Preussen der Antike, «prusianos de la Antigüedad»). En cambio Grote, aunque reconoce que compartía costumbres y aspectos organizativos

re sociale..., op. cit., 175-182.

41. P. Cartledge, Sparta and Lakonia. A Regional History 1300-362 B.C., Londres-Boston-Henley, 1979, 97 propuso que tal vez en esta fértil región se concentraba originalmente el mayor número de hilotas laconios.

42. Así por ejemplo Lévy, Sparte... op. cit., 116-117; ésta es en parte también la tesis de Luraghi, The Ancient... op. cit. (2002 y 2003), para quien el hilotismo es el fruto de homogeneizar situaciones serviles diversas, entre las cuales se encuentra la reducción a la esclavitud del campesinado empobrecido y endeudado. Para M.A. Levi, "Quattro studi spartani”, Rendiconti dell' Istituto Lombardo, 96, 1962, 523-528, por contra, el hilotismo tendría su origen en trabajadores tributarios de época micénica que habrían pasado junto con sus tierras a control espartiata.

43. Vol. II, 374.

44. Plácido, “Nacionalismo..., op. cit., 26-27. 
con otros dorios, notablemente con los cretenses, ve a Esparta idiosincrática, con unas instituciones «peculiares en sí mismas» que llevan la impronta licurguea y que son el resultado de las coyunturas históricas por las que atravesó, convirtiéndola en «el menos indicado de los estados para ser citado como ejemplo de los atributos de clase del dorismo» ${ }^{45}$. Grote pone distancia, así, con el hasta entonces incuestionado axioma de que los hilotas eran aqueos autóctonos subyugados por la espada doria conquistadora. Mas no llega a verse libre del todo de esas ataduras, que afloran por ejemplo en su comentario al discurso de Brasidas durante su campaña en la Calcídica, para la cual el general espartano contó con varios centenares de hilotas armados como hoplitas; Grote, que parece sentir la misma admiración que Tucídides por Brasidas, le define como «un oficial de raza doria, política oligárquica, imperturbable intelecto y estimable carácter», mientras sus hilotas, los llamados brasideos, son «la raza conquistada, no la conquistadora; sin embargo, tan fácilmente el orgullo militar o de regimiento suplanta las simpatías de la raza que estos hombres se sentirían halagados al dirigirse a ellos como si pertenecieran a la raza que había esclavizado a sus ancestros» ${ }^{46}$.

Porque la tesis del Estado racial no se circunscribía a los historiadores alemanes, sino que colegas británicos contemporáneos se vieron «contagiados» intelectualmente. Así, Connop Thirlwall, compañero de pupitre de Grote en la Charterhouse School (Surrey) y a la postre compañero de tumba en la Abadía de Westminster, cotraductor de la Römische Geschichte de Niebuhr en la Universidad de Cambridge y más tarde obispo de St. David's (Gales) y miembro de la Cámara de los Lores, incorpora los resultados de la Philologie y la Altertumswissenschaft teutonas a los ochos volúmenes de su History of Greece (compuesta entre 1835 y 1844) ${ }^{47}$, en la que la virtud y la grandeza espartanas se ligan más al componente genético que a la acción de Licurgo: «Es la contemplación de las instituciones espartanas mismas lo que parece justificar la conclusión de que no fueron tanto el trabajo del arte y la previsión humanas como una forma de sociedad originalmente congénita al carácter del pueblo dorio, a la situación en que se colocaron con sus nuevas conquistas y a sus dotes de liderazgo $»^{48}(. .$.$) «En la raza doria el primitivo$ carácter helénico ha sido moldeado por las circunstancias bajo las cuales el pueblo se

45. Vol II, 342.

46. Vol. VI, 224-225.

47. Sobre Thirlwall, véase J.C. Thirlwall, Connop Thirlwall, Historian and Theologian, Londres, 1936; D. Demetriou, "Bishop Connop Thirlwall: Historian of Ancient Greece", Quaderni di Storia, 56, 2002, 49-90; O. Murray, "British Sparta in the Age of Philhellenism", en N. Birgalias, K. Buraselis y P.A. Cartledge (Eds.), The Contribution of Ancient Sparta to Political Thought and Practice, Atenas, 2007, 372-377.

48. Vol. I, 297. He manejado la edición original. 
formó y ejercitó de una forma peculiar» ${ }^{49}$. En este marco conceptual los hilotas son vistos como «una raza inferior a la que le estaba vedado mancillar o profanar todo lo concerniente al universo de la casta gobernante $»^{50}$. Con todo, Thirlwall coincide con Grote en que, pese a que por naturaleza los dorios no rezuman precisamente humanidad, su trato a los hilotas no se caracteriza por una especial crueldad; destaca por ejemplo que no se les arrancaba de sus casas, como sí le sucedía al campesinado pobre del Ática ${ }^{51}$, e incluso despliega escepticismo hacia las informaciones plutarqueas acerca de la krypteía, como hace Grote (vid. infra), o de la humillación a la que eran sometidos en los syssitia ${ }^{52}$. Donde no alberga dudas, también al igual que Grote y por las mismas razones, es en el relato tucidídeo de la masacre de los dos mil hilotas con el que abríamos este trabajo. Y un punto más de consenso entre ambos historiadores lo encontramos en el origen del hilotismo, pues Thirlwall reconoce que «estamos abandonados a la guía insegura de las conjeturas etimológicas» ${ }^{53}$.

Como acabamos de mencionar, la mente analítica de Grote le lleva a cuestionar la krypteía tal y como es descrita por Plutarco ( $L y k$. 28.2-7), pero sin llegar a negar su existencia, avalada por la «autoridad» de Platón ( $L g .633 \mathrm{~B}-\mathrm{C})$. A su entender consistía en un «sistema policial o de espionaje» integrado por jóvenes espartiatas que vivían en la clandestinidad vigilando las aldeas hilotas y las ciudades periecas para asesinar potenciales elementos subversivos; niega en consecuencia la proclamación de guerra a los hilotas hecha por los éforos antes de proceder a la matanza, «que llevaría la desesperación antes que la tranquilidad a los hilotas», y cree que Plutarco coloreó su relato (el de Queronea invoca como fuente a Aristóteles, pero Grote lo pone en duda arguyendo que éste no lo dice en su Política cuando disecciona el ordenamiento constitucional espartano $)^{54}$. No obstante, como ha señalado Cartledge, existen dos argumentos poderosos en favor de la credibilidad: la proclamación de los éforos propiciaría la necesaria sanción de los dioses al asesinato, evitando el míasma, y, por otro lado, la regularidad de la criptia debía de convertirla en una práctica desgraciadamente «familiar» para las potenciales víctimas ${ }^{55}$. En cualquier caso, Grote se muestra muy atinado al afirmar que los hilotas -él añade a los periecos- no supusieron una amenaza real hasta que la endémica oliganthropía, acelerada por el proceso de concentración de tierras en unos pocos ciudadanos y el em-

\author{
49. Vol. I, 337. \\ 50. Vol. I, 310. \\ 51. Vol. I, 310. \\ 52. Vol. I, 311-312. \\ 53. Vol. I, 309-310. \\ 54. Vol. II, 378-379. \\ 55. Cartledge, “Grote’s Sparta..., op. cit., 263.
}


pobrecimiento y consecuente pérdida de la ciudadanía de otros muchos, hizo estragos en el cuerpo cívico ${ }^{56}$. De hecho, la investigación actual tiende a ver en la criptia una dura prueba ritual e iniciática de orígenes remotos que, por el desarrollo de circunstancias políticas concretas como la necesidad de controlar numérica e ideológicamente a la masa de población hilota, habría sido «reinstitucionalizada» en época clásica ${ }^{57}$.

De otra parte, Grote propende, bien que escuetamente, a destacar la promoción social de los hilotas: aquellos que son manumitidos pasaban a «una clase aparte, conocida en la época de la guerra del Peloponeso como neodamodes», y dado que se habían distinguido por su valentía se procuraba que sirvieran en el exterior, ya sea en las filas del ejército, ya como colonos ${ }^{58}$. Grote no explora la naturaleza de la dependencia de estos neodamodes, ni su situación socioeconómica, tan solo es consciente de la necesidad de mantenerlos alejados de Esparta por el potencial peligro que suponían. De la misma forma, asume de manera natural, sin ulterior explicación, que 700 hilotas sean armados como hoplitas para acompañar a Brasidas en su expedición a la Calcídica tracia ${ }^{59}$ e incluso celebra «la marcada superioridad del carácter griego», pese a ser hilotas, en su choque contra ilirios y macedonios ${ }^{60}$; llega a afirmar, un tanto sorprendentemente y sin cita de fuente alguna, que los hilotas podían alcanzar el puesto de harmosta, una especie de gobernador militar en los territorios ocupados durante el segundo imperio espartano ${ }^{61}$. Ello se debe a que el historiador británico concede a los hilotas una mayor valentía y coraje que a los esclavos, lo que les hacía aptos para el servicio militar e incluso, por inverosímil que parezca, ejercer el man-

56. Vol. II, 360.

57. M.I. Finley, “Esparta”, en Id., Uso y abuso de la historia, Barcelona, 1977 (1975), 255; L. Thommen, Lakedaimonion Politeia. Die Entstehung der spartanischen Verfassung, Historia Suppl. 103, Stuttgart, 1996, 128-129; M.A. Flower, “The Invention of Tradition in Classical and Hellenistic Sparta”, en Powell y Hodkinson, Sparta: Beyond... op. cit., 206-207. El momento de esa «reinstitucionalización» sería la derrota en Leuctra y la consiguiente pérdida de Mesenia en opinión de J. Christien, "Les temps d'une vie. Sparte, une société à classe d'âge", Mètis, 12, 1997, 71-72, S. Link, "Zur Entstehungsgeschichte der Spartanischen krypteia", Klio, 88, 2006, 34-43, N. Birgalias, "La cohesion sociale à Sparte au $\mathrm{IV}^{\mathrm{e}}$ siècle", en J. Christien y B. Legras (Eds.), Sparte hellénistique - IVe-IIIe siècles avant notre ère, Dialogues d' Histoire Ancienne, Suppl. 11, Besançon, 2014, 17 y J.-C. Couvenhes, «Les kryptoi spartiates...», op. cit., 66-68; sin embargo, P. Cartledge, "A Spartan Education", en Apodosis: Essays Presented to Dr. W.W. Cruickshank, Londres, 1992, 18 no ve motivos que descarten que la criptia fuese, desde su mismo nacimiento a mediados del siglo VII, un medio de conjurar, o al menos reducir, el peligro hilota.

58. Vol. II, 379; cf. vol. VI, 292; IX, 79.

59. Vol. VI, 148, 175.

60. Vol. III, 421.

61. Vol. IX, 21. 
$\mathrm{do}^{62}$. Efectivamente, lo que en Grote solo se atisba pero no se desarrolla, al vincular el destino de los neodamódeis con el de los hypomeíones o «inferiores», es que una Esparta incapaz de que su reducido y exclusivista cuerpo cívico soportara el peso de las necesidades imperiales multiplicó categorías y subcategorías sociales (neodamódeis, hypomeíones, desposionaûtai, trésantes, móthakes, nóthoi, tróphimoi, aphétai, adéspotoi, eryktêres) que únicamente tenían en común su marginación política y económica con respecto a los hómoioi y el aprovechamiento militar del que eran objeto, para acabar convirtiéndose en carne de mercenariado ${ }^{63}$.

Es más, a Grote se le escapa el que presumiblemente fue el primer caso de liberación de hilotas en nuestras fuentes, el representado por los epeúnactoi (literalmente «sustitutos de lecho»). Según Teopompo (FGrH 115F171 apud Ath. 271C-D), las elevadas pérdidas humanas durante la guerra contra los mesenios -no especifica cuálforzaron a los espartanos a conceder la libertad y la ciudadanía a un cierto número de hilotas mediante un extraño rito por el cual éstos ocupaban los lechos de campaña de los espartiatas caídos en combate, de donde tomarían el nombre ${ }^{64}$. Que la integración en la comunidad cívica no fue completa lo testimonia, además de una designación infamante, la tradición recogida por Diodoro (8.21), en la que estos epeunactos se ven involucrados en la revuelta social que siguió a la primera guerra mesenia, la protagonizada por Falanto y los partheníai (hijos bastardos nacidos mientras los espartiatas combatían en Mesenia), cuya salida forzada de Esparta desembocará en la fundación de Taras. Sin embargo, Grote sigue a Antíoco de Siracusa (FGrH 555F13 apud Str. 6.3.2) en pensar que los epeunactos serían lacedemonios «degradados al rango y servidumbre de hilotas» por haber incumplido el juramento de no regresar a Esparta hasta que Mesenia estuviera sometida por completo y, en consecuencia, los partenias constituirían su progenie ${ }^{65}$; Estrabón, que aúna el relato de Antíoco con el de Éforo de Cime (FGrH 70F216), prefiere, como Grote, dignificar la historia de la fundación de Tarento eliminando el elemento hilota de la misma.

Como conclusión, podemos decir que el papel jugado por los hilotas en la History of Greece de George Grote fue deudor del plan general de la obra, cuya finalidad

62. Vol. II, 376.

63. Sobre la progresiva incorporación al ejército lacedemonio de estos grupos dependientes, véase F. Ruzé, "Les inférieurs libres à Sparte: exclusion ou integration?", en Mélanges Pierre Lévêque, París, 1993, VII, 299-301 y P. Carlier, “Les Inférieurs et la politique extérieure de Sparte”, en Mélanges P. Lévêque, VIII, París, 1994, 25-41.

64. Cf. A. Paradiso, "Gli epeunatti spartani”, Index, 12, 1983-84, 355-365, que postula que estos hilotas manumitidos desposarían también a las viudas de los espartiatas fallecidos.

65. Vol. III, 383-384. 
principal era contrarrestar la poderosa influencia de las primeras historias «académicas» de la Grecia antigua, la de John Gillies (1786) y, sobre todo, la de William Mitford (1784-1810); con las revoluciones americana y francesa bien recientes para establecer convenientes analogías con Atenas, ambas coincidían en su aversión hacia los excesos de una democracia convertida en oclocracia, en el poder de la turba, en virtud del desorden e inestabilidad que propician los caprichos de una muchedumbre voluble e ignorante, acéfala, mientras aprobaban el orden, la estabilidad, el patriotismo y las instituciones de Esparta, mostrando condescendencia hacia un hilotismo sin el cual se tornaba imposible cumplir el ideal licurgueo, que traducido en palabras de Mitford era que «cada lacedemonio fuera, en el más estricto sentido del término moderno, un caballero, sin negocios» ${ }^{66}$. Grote tampoco acomete un análisis del hilotismo, se limita a sacarlo de su «invisibilidad» cuando es preciso poner el foco sobre las oscuras entrañas, la crueldad, la esterilidad cultural y la militarización que, desde su punto de vista, presidían el kósmos espartano. Como tantos otros, el ilustre historiador victoriano se benefició de la precaria y sesgada información antigua en torno a los hilotas, que todavía hoy alienta el debate ideológico e historiográfico sobre su condición y hace bueno el reciente aserto de Nino Luraghi y Sue Alcock: «La última palabra sobre los hilotas nunca se pronunciará y está en la naturaleza de la evidencia que cualquier cosa que se diga sobre ellos ha de ser conjetural, provisional y verdaderamente controvertida $»^{67}$.

66. Citado por Turner, The Greek... op. cit., 196-197. Mitford tenía el convencimiento de que ni la libertad ni la propiedad quedaban garantizadas por ley bajo los regímenes democráticos (de ahí su extraña laudatio de los Treinta Tiranos en Atenas o del «despotismo ilustrado» de Filipo II). Cf. Demetriou, George Grote... op. cit., 33-46, que se refiere a estas obras como «vehículos para manifiestos políticos inspirados en el pánico hacia la ideas y objetivos revolucionarios» que amenazaban el statu quo alcanzado con la Gloriosa en 1688 (la cita es de la p. 33); A. Ataç, "Imperial Lessons from Athens and Sparta: Eighteenth-Century British Histories of Ancient Greece", History of Political Thought, 27, 2006, 642-660; G. Ceserani, "Modern Histories of ancient Greece: Genealogies, contexts and eighteenth-century narrative historiography”, en A. Lianeri (Ed.), The Western Time of Ancient History. Historiographical encounters with the Greek and Roman Pasts, Cambridge, 2011, 138-156.

67. En la introducción al volumen sobre el hilotismo que ambos coeditan (Luraghi y Alcock, Helots... op. cit., s.p). 